\title{
Avaliação da qualidade de serviços de uma biblioteca universitária: um estudo de caso utilizando o modelo Servqual
}

\author{
André Luís Policani Freitas \\ Doutor em engenharia de produção pela Universidade Estadual do \\ Norte Fluminense (UENF). \\ E-mail: andrepolicani@yahoo.com \\ Franz Marx Carvalho Bolsanello \\ Engenheiro de produção (Universidade Estadual do Norte \\ Fluminense). Atua na área de gestão da qualidade. \\ E-mail: fmbolsanello@yahoo.com.br
}

\section{Nathália Ribeiro Nunes Gomes Viana}

Engenheira de produção (Universidade Estadual do Norte Fluminense). Atua na área de gestão da qualidade.

E-mail: nathiviana@gmail.com

\section{Resumo}

Nas últimas duas décadas, pesquisadores em ciência da informação têm investigado o valor dos serviços em bibliotecas de acordo com as percepções, expectativas e necessidades dos usuários. No Brasil, a avaliação de bibliotecas universitárias tem desempenhado um importante papel nas avaliações das instituições de educação superior e dos cursos de graduação. Neste contexto, é essencial que exista um procedimento eficiente para monitorar a qualidade dos serviços prestados por bibliotecas universitárias. Visando a contribuir para esta questão, este trabalho utilizou o modelo Servqual para avaliar a qualidade dos serviços de uma biblioteca de uma universidade. Através de um estudo de caso, foram identificadas as fraquezas/ potencialidades e os aspectos críticos que devem ser priorizados para melhorar a qualidade dos serviços prestados.

\section{Palavras-chave}

Bibliotecas universitárias. Qualidade em servicos. Servqual.

\section{Evaluating service quality of an academic library: a case study using the Servqual model}

\section{Abstract \\ Over the last two decades, researchers in Information Science have investigated the value of library services according to the user's perceptions, expectative and needs. In Brazil, the evaluation of academic libraries has played an important role in the evaluation of the performance of Universities and University Degree Courses. In this context, it's essential that exists an efficient procedure for monitoring the service quality provided by academic libraries. In order to contribute to this issue, this work used the Servqual model for evaluating the service quality of an academic library. By conducting a case study, the weaknesses/potentialities and the critical points which must be priority in order to improve the Service Quality were identified. \\ Keywords}

Academic libraries. Service quality. Servqual.

\section{INTRODUÇÃO}

Por muitos anos, pesquisadores em ciência da informação e bibliotecas têm investigado as necessidades de informação, os desejos dos usuários e as percepções dos usuários a respeito do valor dos serviços prestados por bibliotecas (NITECKI; HERNON, 2000). Em geral, as pesquisas realizadas neste contexto buscam avaliar a qualidade em termos do acervo das bibliotecas (quantidade de títulos, relevância dos títulos e variedade dos assuntos presentes nos títulos) e a eficácia dos serviços por elas prestados, dentre as quais são citadas as realizadas por Chang e Hsieh (1997), Chivers e Thebridge (2000), Nitecki e Hernon, (2000), Cook e Thompson (2000), Snoj e Petermanec (2001), Gaten (2004) e, mais recentemente, por Satoh et alii (2005). Nota-se também que nos tempos atuais torna-se cada vez mais importante que as bibliotecas sejam informatizadas, permitindo aos funcionários e usuários consultar mais facilmente a base de dados do acervo.

No Brasil, destacam-se os esforços direcionados à avaliação de bibliotecas universitárias no âmbito do Sistema Nacional de Avaliação da Educação Superior (Sinaes). O Sinaes foi criado por meio da Lei no 10.861 , de 14 de abril de 2004, que instituiu a avaliação das instituições de educação superior (IES), de cursos de graduação e do desempenho dos estudantes de forma integrada (INEP, 2004).

No âmbito do Sinaes, os cursos de graduação devem ser avaliados à luz de três grandes categorias: "organização didático-pedagógica”, "corpo docente, corpo discente e corpo técnico-administrativo" e "instalações físicas”. Em especial, a avaliação de bibliotecas é formalizada por meio de um indicador que detém 50\% dos pontos referentes à categoria "instalações físicas", categoria à qual é atribuída $25 \%$ da pontuação das categorias (INEP, 2006). Neste sentido, observa-se que a avaliação de bibliotecas é de suma relevância na constituição do conceito final das avaliações de cursos de graduação, devendo ser objeto de pesquisa de instituições de educação superior e das coordenações dos cursos de graduação. 
Nas últimas décadas, diversos modelos têm sido desenvolvidos com o intuito de mensurar a qualidade de serviços, considerando o cliente como foco principal destas avaliações, dentre os quais se destacam o modelo dos 5 Gaps (PARASURAMAN et alii, 1985), o modelo Servqual (PARASURAMAN et alii, 1988) e o modelo Servperf (Cronin; Taylor, 1992). Apesar da existência de tais modelos, estes geralmente apresentam uma abordagem genérica, sendo essencialmente necessário adaptá-los para a natureza do serviço a ser avaliado.

Desejando contribuir para o tratamento do problema de avaliação da qualidade de serviços prestados por bibliotecas, este artigo busca avaliar a qualidade dos serviços prestados por uma biblioteca de uma universidade utilizando o modelo Servqual adaptado para a avaliação de serviços desta natureza. Mais especificamente, em um estudo de caso, pretende-se identificar, dentre outros aspectos, (i) os itens mais críticos nos serviços prestados pela biblioteca em questão, segundo a percepção de alunos dos cursos de graduação (cursos diurnos) e dos cursos de licenciatura (cursos noturnos), e (ii) oportunidades de melhorias e ações que possam contribuir para tal, com a participação do administrador da biblioteca.

Sucintamente, este artigo está estruturado da seguinte forma: a seção 2 aborda as principais características dos serviços e alguns dos principais modelos utilizados na avaliação da qualidade de serviços; a seção 3 descreve aspectos relacionados aos serviços prestados por bibliotecas; a seção 4 apresenta o estudo de caso no qual o modelo Servqual foi utilizado para avaliar os serviços de uma biblioteca universitária; a seção 5 apresenta as considerações finais e, no apêndice, apresenta-se o modelo de questionário utilizado no estudo de caso.

\section{AVALIAC̣ÃO DA QUALIDADE DE SERVIÇOS}

Apesar de muito abordado em pesquisas científicas, o tema "qualidade em serviços" ainda é objeto de muita discussão e questionamento entre pesquisadores, gerentes e administradores (FREITAS, 2005). Em sua essência, este questionamento é decorrente do envolvimento de dois objetos de entendimento não tão trivial: qualidade e serviços.

Com o intuito de contribuir para a compreensão do significado de "serviços", diversos autores têm identificado características relacionadas a este tema, dentre os quais se destacam Parasuraman et alii (1988), que apresentam três características dos serviços:
- simultaneidade: serviços são consumidos quase que simultaneamente ao momento em que são produzidos, tornando difícil ou quase impossível detectar e corrigir as falhas antes que elas ocorram e afetem o cliente (no contexto de serviços bibliotecários; o cadastramento errado de uma obra possivelmente apenas será detectada no momento em que esta for solicitada por um usuário);

- intangibilidade: os serviços representam um produto não físico, ou seja, não podendo ser transportados e/ou armazenados, (por exemplo, uma obra reservada pelo usuário pode ser útil a este somente em um período específico, não podendo ser adiada para uma outra ocasião);

- heterogeneidade: a grande variedade de serviços existentes e o forte relacionamento com o fator humano dificultam a atividade de padronização e estimação de preços (em geral, bibliotecas possuem diferentes regras para os serviços de consulta, empréstimo e utilização de suas dependências -, fatos que costumam causar desentendimentos entre usuários e funcionários).

Segundo Cronin e Taylor (1992), a busca pela excelência em serviços e a mensuração da qualidade dos serviços têm sido uma estratégia efetivamente utilizada por organizações para a obtenção da "vantagem competitiva". Neste contexto, ao longo dos anos diversos modelos foram desenvolvidos com o intuito de avaliar a qualidade dos serviços, dentre os quais se destacam o modelo dos 5 Gaps (PARASURAMAN et alii, 1985), o modelo Servqual (PARASURAMAN et alii, 1988) e o modelo Servperf (CRONIN; TAYLOR, 1992).

O modelo dos 5 Gaps (Lacunas) foi desenvolvido com o intuito de auxiliar os gestores a compreender as fontes dos problemas da qualidade dos serviços e como melhorálos (vide Figura 1). De maneira breve, os Gaps buscam mensurar a discrepância entre:

- as expectativas dos clientes e as percepções dos gerentes sobre estas expectativas (Gap 1);

- as percepções dos gerentes em relação às expectativas dos clientes e as especificações da qualidade do serviço (Gap 2);

- as especificações da qualidade do serviço e a qualidade do serviço prestado (Gap 3);

- o serviço realmente prestado e o que é comunicado ao cliente a respeito deste (Gap 4); 
- as expectativas dos clientes em relação ao serviço e a percepção destes em relação ao desempenho do serviço prestado (Gap 5).

Considerando o modelo dos 5 Gaps, nota-se que estes podem ser mensurados separadamente. Entretanto, a mensuração do Gap 5 constitui-se na essência da utilização do modelo Servqual, desenvolvido por Parasuraman et alii (1988). O modelo (ou escala) Servqual é constituído por 22 itens que compõem as cinco dimensões ou determinantes da qualidade, que englobam as dez dimensões anteriormente apresentadas por Parasuraman et alii (1985):

- confiabilidade: confiabilidade de um serviço é a capacidade de prestar o serviço de forma confiável, precisa e consistente. É uma dimensão importante para a qualidade dos serviços bibliotecários, pois informações corretas e precisas impactam fortemente na qualidade dos trabalhos acadêmicos e científicos;

- receptividade: é a disposição de prestar os serviços prontamente e auxiliar os usuários, caracterizando-se por agilidade no atendimento, eficiência em resolver os problemas, atenção personalizada e a cortesia dos funcionários;

- segurança (abrange as dimensões competência, cortesia, credibilidade e segurança): Refere-se à isenção de qualquer falha, risco ou problema e relaciona-se com o conhecimento e cortesia dos funcionários e sua capacidade de inspirar confiança;

- aspectos tangíveis: refere-se à aparência de qualquer evidência física do serviço bibliotecário, ou seja, a aparência limpa ou a forma de se vestir dos funcionários, a limpeza das instalações, o estado de conservação do acervo, a atualização e inovação de novos equipamentos e facilidade no acesso às instalações;

- empatia (acesso, comunicação e entendimento do cliente): a empatia fornece atenção individualizada aos usuários das bibliotecas, buscando atender às suas necessidades específicas. Dentre os requisitos relacionados a esta dimensão, citam-se localização conveniente, acesso sinalizado, divulgação do horário de funcionamento e regras de utilização dos serviços. Freqüentemente existe o contato direto entre o usuário e os funcionários das bibliotecas. Entretanto, com o advento da tecnologia da informação, este contato tem sido realizado virtualmente por meio de novos recursos de comunicação, tais como o acesso a homepage da biblioteca e a comunicação por e-mail;

O emprego do Servqual é realizado em duas etapas: na primeira etapa, são mensuradas as expectativas prévias dos clientes em relação ao serviço; na segunda etapa, são mensuradas as percepções dos clientes acerca do desempenho do serviço prestado.

FIGURA 1

Modelo dos 5 Gaps da qualidade em serviço

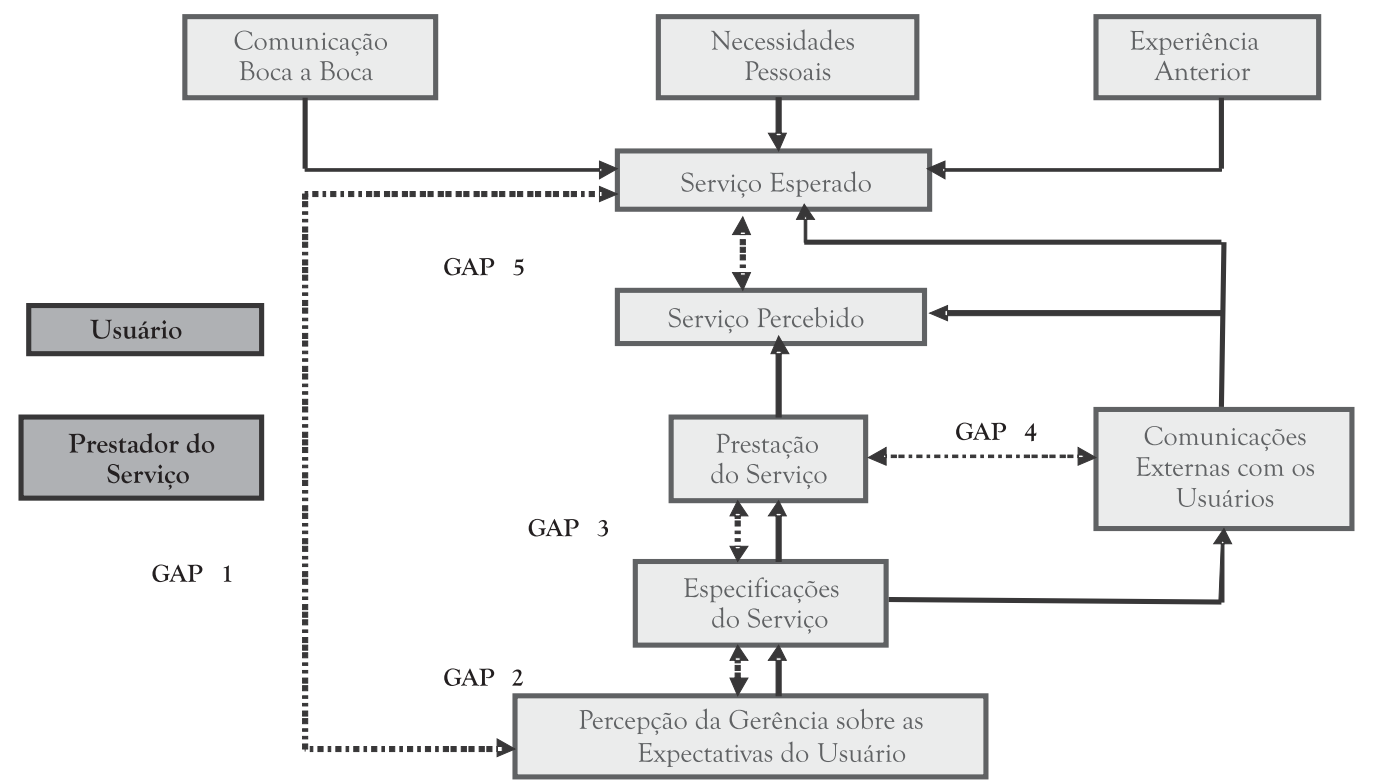

Fonte: adaptado de Parasuraman et alii. (1985). 
Em geral, as avaliações são realizadas com o emprego de um questionário que utiliza uma escala do tipo Likert de 7 pontos, cujos extremos são definidos com os conceitos "Discordo Totalmente" e "Concordo Totalmente". Para cada item do questionário, calcula-se o Gap 5, definido pela diferença entre a percepção de cada avaliador acerca do desempenho ( $\mathrm{P}$, originado de Performance) do serviço prestado e as sua Expectativa (E) quanto à prestação do serviço. Um item com Gap negativo indica que o desempenho está abaixo da expectativa, revelando que à luz deste item o serviço prestado está gerando um resultado insatisfatório para os clientes. Por outro lado, um item com Gap positivo indica que o prestador de serviços está prestando um serviço superior ao esperado à luz deste item, sendo um aspecto de satisfação do cliente. Dentre outros aspectos, este modelo permite:

- avaliar a qualidade do serviço à luz de cada uma das cinco dimensões da qualidade, medindo as pontuações obtidas nos itens que compõem cada dimensão;

- fornecer uma medida geral da qualidade dos serviços pela média da pontuação de todas as dimensões;

- identificar, em vários tipos de serviços, os pontos fortes e fracos da organização, servindo de base para a melhoria contínua da qualidade dos serviços;

- comparar um determinado serviço aos serviços dos concorrentes, identificando em quais dimensões este é superior aos concorrentes e em quais dimensões precisa ser aprimorado.

Por outro lado, diversos autores criticam o modelo Servqual. Por exemplo, Finn e Lamb (1991) relataram que as cinco dimensões do Servqual não eram suficientes para representar a qualidade no setor de varejo, sendo necessária a realização de novos estudos para auxiliar no desenvolvimento e refinamento das dimensões da qualidade. A mesma constatação foi defendida por Cronin e Taylor (1992), em seu estudo envolvendo bancos, lavanderias, dedetizadoras e empresas de fast food.

No Servqual original as dimensões eram tratadas como sendo de igual importância. Parasuraman et alii (1994) reconheceram tal problema e propuseram uma pergunta adicional na referida escala, em que o usuário deveria dividir 100 pontos entre as cinco dimensões, definindo sua importância relativa. Porém, os pesquisadores ainda questionam se a simples inclusão dessa pergunta adicional realmente solucionaria o problema.
Entretanto, a maior crítica ao Servqual é oriunda dos trabalhos de Babakus e Boller (1992), Carman (1990) e Cronin e Taylor (1992), que argumentaram que o uso da diferença entre percepções e expectativas (P - E) não traz informações adicionais sobre a qualidade do serviço, visto que estas já estavam contidas no componente das percepções. Em especial, Cronin e Taylor (1992) afirmaram que o Servperf, modelo por eles proposto e baseado apenas em medidas da percepção de desempenho do serviço, seria mais adequado para avaliar a qualidade de serviços.

Apesar das críticas e deficiências creditadas ao modelo Servqual, é inquestionável o seu impacto no âmbito da avaliação da qualidade de serviços, sendo o modelo mais amplamente aplicado em diversos setores, com resultados positivos, satisfatórios e práticos. Especificamente no âmbito da avaliação da qualidade de serviços em bibliotecas, o Servqual tem sido implementado computacionalmente pelo software LibQUAL $+\AA$, cuja utilização deve ser registrada e remunerada. Segundo a ARL - Association of Research Libraries (2008), mais de 500 bibliotecas têm utilizado o LibQUAL+ß.

\section{SERVIÇOS EM BIBLIOTECA}

Em um mundo cada vez mais globalizado e competitivo, a capacidade de extrair informações relevantes a partir de uma base de dados é um dos principais elementos que contribuem para o sucesso na gestão das organizações (FREITAS et alii, 2006). Este cenário também se encontra caracterizado na gestão de bibliotecas universitárias.

Em especial, com a evolução da área de conhecimento denominada tecnologia da informação, novos serviços têm sido disponibilizados aos usuários das bibliotecas, dentre os quais o serviço de reserva de livros pela Internet, o serviço de empréstimo domiciliar, o serviço de consulta à base de dados das bibliotecas (consulta ao acervo realizada in loco ou pela Internet, utilizando recursos de busca por título, por autor, por palavras-chave etc.), consulta ao Portal de Periódicos da Coordenação de Aperfeiçoamento Pessoal de Nível Superior (Capes) e também o acesso à Internet para fins de pesquisa. Vale ressaltar também que nos últimos anos as dissertações de mestrado e teses de doutorado têm sido disponibilizadas em formato digital (muito em breve os trabalhos de conclusão de cursos de graduação e licenciatura também deverão estar disponíveis nesse formato). 
Neste contexto, nos tempos atuais, a qualidade dos serviços prestados em bibliotecas não está atrelada somente ao desempenho dos funcionários e da estrutura física existente nestas, mas também aos recursos computacionais (hardware e software) que compõem o sistema de informação.

Diversos estudos têm sido desenvolvidos visando a avaliar a qualidade dos serviços em bibliotecas, tendo como foco principal a opinião dos usuários (estudantes de cursos de graduação/pós-graduação, funcionários e docentes). Algumas contribuições destes estudos encontram-se brevemente descritas na tabela 1 , a seguir. Em geral, estes estudos objetivam:

- identificar o perfil dos usuários que utilizam as bibliotecas, captando seus atributos, hábitos e serviços que mais utilizam;
- mensurar a qualidade dos serviços à luz de diversos itens/critérios relevantes, buscando captar dos usuários as suas expectativas acerca do serviço a ser prestado e as percepções em relação ao desempenho do serviço executado (as principais metodologias utilizadas para este fim foram descritas na seção 2) em bibliotecas específicas;

- identificar as dimensões e critérios/indicadores que melhor se ajustam à avaliação da qualidade dos serviços em bibliotecas, segundo a opinião dos usuários;

- propor abordagens e metodologias para avaliar a qualidade de serviços em bibliotecas;

- propor ações (corretivas e preventivas) com o intuito de melhorar a qualidade dos serviços prestados em bibliotecas, visando a atender às necessidades e expectativas dos usuários.

TABELA 1

Artigos com o foco na avaliação da qualidade dos serviços em bibliotecas

\begin{tabular}{c|c}
\hline Pesquisas & \multicolumn{1}{c}{ Contribuições } \\
\hline $\begin{array}{c}\text { Chang e } \\
\text { Hsieh (1997) }\end{array}$ & $\begin{array}{l}\text { O artigo busca identificar o perfil dos usuários das bibliotecas em Taiwan e determinar o grau de envolvimento } \\
\text { destes com os serviços prestados pelas bibliotecas. Propuseram uma abordagem para facilitar a divulgação do uso } \\
\text { das bibliotecas no país, assegurando que a qualidade dos serviços prestados atende às necessidades dos usuários. }\end{array}$
\end{tabular}

Andaleeb e Simmonds (1998)

Chivers e Thebridge (2000)

Nitecki e Hernon (2000)

Cook e Thompson (2000)

Snoj e Petermanec (2001)
O artigo propõe e testa um modelo de cinco fatores para explicar a satisfação dos usuários com bibliotecas universitárias. Os autores identificaram que uma nova dimensão denominada "demeanor" era um importante aspecto dos serviços em bibliotecas e que é uma combinação de duas dimensões do Servqual (empatia e segurança) e vários outros itens. A nova dimensão está associada à sensibilidade dos funcionários para necessidades do usuário, disposição para ouvir seus problemas, sendo educado, cortês, simpático e calmo.

$\mathrm{O}$ artigo destaca que os métodos de pesquisa estão sendo cada vez mais solicitados pelos administradores de bibliotecas públicas para direcionar os serviços em termos estratégicos e operacionais. Identifica áreas nas quais a pesquisa deve ser mais bem compartilhada e incorporada, sugerindo uso de recursos públicos a serem usados pelos administradores para a melhoria de desempenho.

Desenvolveram um instrumento para identificar os critérios mais importantes segundo a opinião dos usuários e as percepções destes em relação aos serviços prestados. Afirmam que o Servqual não é adequado para avaliar a satisfação dos usuários, mas é relevante para avaliar o desempenho das bibliotecas segundo a opinião destes.

Avaliaram a confiabilidade e a validade do Servqual a partir de uma pesquisa de três anos, realizada com os usuários de uma biblioteca universitária. Os resultados indicaram que os scores obtidos são altamente confiáveis, mas as cinco dimensões do Servqual não foram totalmente atendidas - como conseqüência, a validade do modelo tradicional pode ser questionada quando aplicada à pesquisas em bibliotecas. Acreditam que pode haver três dimensões em bibliotecas (aspectos tangíveis, confiabilidade ou eficiência do serviço, e influência do serviço), mas pesquisas mais profundas precisam ser conduzidas para confirmar esta suposição. Recomendaram cautela aos administradores no uso do Servqual (com as cinco dimensões) em bibliotecas e a verificação periódica da confiabilidade dos scores obtidos em pesquisas.

O artigo avaliou o nível da qualidade dos serviços de uma biblioteca universitária na Eslovênia, reportando as principais ações que devem ser implementadas para a melhoria da qualidade dos serviços. 
Avaliação da qualidade de serviços de uma biblioteca universitária: um estudo de caso utilizando o modelo Servqual

TABELA 1 (conclusões)

\begin{tabular}{|c|c|}
\hline Pesquisas & Contribuições \\
\hline $\begin{array}{c}\text { Vergueiro e } \\
\text { Carvalho (2001) }\end{array}$ & $\begin{array}{l}\text { O artigo discute a proposição de indicadores de qualidade para serviços de informação que incorporem, } \\
\text { simultaneamente, os pontos de vista de administradores e de clientes de bibliotecas universitárias. A partir de } \\
\text { indicadores presentes na literatura científica, uma pesquisa é realizada no âmbito da área odontológica, revelando } \\
\text { aqueles que se aplicam a essa realidade, além de sugerir ações para a melhoria da qualidade dos serviços em } \\
\text { instituições de ensino superior. }\end{array}$ \\
\hline $\begin{array}{l}\text { Santos et alli } \\
\text { (2003) }\end{array}$ & $\begin{array}{l}\text { Uma técnica de gestão de processos denominada Servpro é proposta com o objetivo de dar suporte à melhoria da } \\
\text { qualidade em serviços, em especial os serviços de bibliotecas. Segundo os autores, a técnica abrange somente os } \\
\text { processos de que o usuário participa (processos de linha de frente), pois considera que a melhoria da qualidade em } \\
\text { serviços ocorre a partir das atividades que são percebidas pelo usuário. Um estudo de caso foi realizado em uma } \\
\text { biblioteca universitária com o intuito de investigar a aplicabilidade da técnica. }\end{array}$ \\
\hline $\begin{array}{l}\text { Gate } \\
(2004)\end{array}$ & $\begin{array}{l}\text { O artigo utilizou o LibQUAL+® para avaliar o impacto de um consórcio de bibliotecas acadêmicas sobre as } \\
\text { percepções dos serviços experimentados pelos usuários membros das instituições participantes. }\end{array}$ \\
\hline $\begin{array}{l}\text { Sampaio et alli } \\
\text { (2004) }\end{array}$ & $\begin{array}{l}\text { O artigo descreve a experiência de implantação do PAQ - Programa de Avaliação da Qualidade dos Produtos e } \\
\text { Serviços do Sistema Integrado de Biblioteca da Universidade de São Paulo (SIBi/USP) e apresenta parte dos } \\
\text { resultados obtidos na pesquisa fundamentada no emprego do modelo Servqual. A análise dos questionários } \\
\text { aplicados e das entrevistas permitiu identificar aspectos a serem implementados com o intuito de aperfeiçoar a } \\
\text { metodologia empregada e também identificar indicadores que poderão ser incluídos nas próximas etapas do } \\
\text { programa. }\end{array}$ \\
\hline $\begin{array}{l}\text { Satoh et alli } \\
\quad(2005)\end{array}$ & $\begin{array}{l}\text { O artigo identificou quatro dimensões e seus indicadores que melhor se adequam à avaliação dos serviços em } \\
\text { bibliotecas universitárias segundo a opinião dos usuários. }\end{array}$ \\
\hline $\begin{array}{l}\text { Silva et alli } \\
\text { (2006) }\end{array}$ & $\begin{array}{l}\text { Propõem um modelo de gestão fundamentado no uso de indicadores que reúne três funções organizacionais } \\
\text { desdobradas em seis elementos: proposta (identificação do valor da informação para o usuário); comunicação } \\
\text { (interface capaz de mensurar os níveis de percepção/satisfação do cliente, bem como permitir a vinculação do } \\
\text { fluxo informacional da biblioteca para o usuário e vice-versa - marketing), e efetivação (atividades que representam } \\
\text { o ciclo de serviço, a gestão da produção de demandas informacionais e as estratégias nos processos). }\end{array}$ \\
\hline $\begin{array}{c}\text { Valls e } \\
\text { Vergueiro (2006) }\end{array}$ & $\begin{array}{l}\text { Os autores descrevem a evolução da gestão da qualidade em serviços de informação no Brasil, destacando, por } \\
\text { meio de revisão de literatura nacional, os principais trabalhos publicados e divulgados a partir de 1997, bem como } \\
\text { os enfoques abordados por tais trabalhos. O artigo visa a contribuir para o avanço das discussões a respeito da } \\
\text { aplicação da gestão da qualidade em serviços de informação no Brasil e adicionar um novo estudo teórico sobre } \\
\text { o tema, que representa a continuidade do trabalho realizado por Valls e Vergueiro (1998). }\end{array}$ \\
\hline
\end{tabular}

Neste sentido, é possível observar que ainda não há um consenso entre os pesquisadores a respeito de quais (e quantas) dimensões são mais adequadas para avaliar a qualidade dos serviços em bibliotecas universitárias. Mais especificamente, há autores que recomendam o uso das cinco dimensões do modelo Servqual tradicional, outros que condenam o uso das cinco dimensões e outros que propõem novas dimensões para este fim.

Observa-se também que a avaliação da qualidade de serviços em bibliotecas é um tema que também têm sido de interesse de pesquisa por parte de administradores e pesquisadores no Brasil, principalmente a partir do início da década de 1990 (sob este aspecto, destacam-se os trabalhos de Valls e Vergueiro (1998) e de Valls e
Vergueiro (2006), que apresentam uma síntese dos artigos científicos nacionais publicados, respectivamente, nos períodos de 1991 a 1996 e 1997 a 2006, buscando agrupálos segundo os enfoques desenvolvidos).

Entretanto, a discussão dos aspectos anteriormente citados não está no escopo e no contexto do presente artigo. Em especial, este artigo visa a contribuir para as pesquisas direcionadas ao tratamento do problema de avaliação da qualidade de serviços prestados por bibliotecas - o modelo Servqual foi adaptado para avaliar a qualidade dos serviços prestados por uma biblioteca de uma universidade, e o estudo de caso realizado será apresentado na seção seguinte. 


\section{O ESTUDO DE CASO}

Este estudo foi realizado com o intuito de avaliar os serviços prestados pela biblioteca do Centro de Ciência e Tecnologia (CCT) da Universidade Estadual do Norte Fluminense (Uenf), segundo o ponto de vista de seus usuários. Sucintamente, neste estudo foram realizadas as etapas apresentadas a seguir.

\section{Desenvolvimento do questionário}

Neste estudo foi elaborado um modelo de questionário para autopreenchimento, estruturado, não disfarçado e com questões fechadas. O desenvolvimento deste questionário foi fundamentado nas dimensões e itens do modelo Servqual, sendo adaptado para a natureza do serviço avaliado e composto por duas partes com 22 itens cada. A primeira parte visava a captar as expectativas (E) dos usuários quanto ao serviço prestado por uma biblioteca considerada "ideal", e a segunda parte, as percepções destes usuários quanto o desempenho $(\mathrm{P})$ dos serviços prestados pela biblioteca do CCT (o Anexo apresenta o modelo de questionário no qual se empregou a escala tipo Likert de 5 pontos);

\section{Coleta de dados (aplicação do questionário)}

Durante três semanas, o questionário foi aplicado a uma amostra de 210 usuários da biblioteca, alunos dos cursos de graduação (cursos que funcionam no período diurno)

TABELA 2

Desempenhos médios, expectativas médias e Gaps médios (engenharias)

\begin{tabular}{c|c|c|c|c|c|c|c|c|c|c|c|c|c|c|c|c|c|c|c|c|c|c}
\hline \multicolumn{10}{c}{} \\
\hline & $\mathbf{I}_{1}$ & $\mathbf{I}_{2}$ & $\mathbf{I}_{3}$ & $\mathbf{I}_{4}$ & $\mathbf{I}_{5}$ & $\mathbf{I}_{6}$ & $\mathbf{I}_{7}$ & $\mathbf{I}_{8}$ & $\mathbf{I}_{9}$ & $\mathbf{I}_{10}$ & $\mathbf{I}_{11}$ & $\mathbf{I}_{12}$ & $\mathbf{I}_{13}$ & $\mathbf{I}_{14}$ & $\mathbf{I}_{15}$ & $\mathbf{I}_{16}$ & $\mathbf{I}_{17}$ & $\mathbf{I}_{18}$ & $\mathbf{I}_{19}$ & $\mathbf{I}_{20}$ & $\mathbf{I}_{21}$ & $\mathbf{I}_{22}$ \\
\hline $\bar{P}$ & 2,80 & 3,10 & 3,30 & 2,50 & 3,25 & 3,50 & 3,10 & 3,93 & 3,91 & 3,92 & 3,79 & 3,99 & 3,77 & 3,51 & 3,51 & 3,84 & 3,40 & 3,60 & 3,24 & 1,88 & 3,50 & 3,93 \\
\hline $\bar{E}$ & 4,71 & 4,76 & 4,87 & 4,86 & 4,84 & 4,73 & 4,90 & 4,86 & 4,71 & 4,80 & 4,86 & 4,86 & 4,12 & 4,39 & 4,61 & 4,58 & 4,64 & 3,74 & 4,38 & 4,69 & 4,79 & 4,90 \\
\hline \multirow{2}{*}{$\mathrm{G}$} & - & - & - & - & - & - & - & - & - & - & - & - & - & - & - & - & - & - & - & - & - & - \\
\cline { 2 - 14 } & 1,91 & 1,67 & 1,56 & 2,36 & 1,59 & 1,23 & 1,80 & 0,92 & 0,79 & 0,88 & 1,06 & 0,87 & 0,38 & 0,86 & 1,09 & 0,74 & 1,25 & 0,19 & 1,14 & 2,75 & 1,30 & 0,96 \\
\hline
\end{tabular}

TABELA 3

Desempenhos médios, expectativas médias e Gaps médios (licenciaturas)

Itens de Avaliação

\begin{tabular}{|c|c|c|c|c|c|c|c|c|c|c|c|c|c|c|c|c|c|c|c|c|c|c|}
\hline & $\mathrm{I}_{1}$ & $\mathrm{I}_{2}$ & $\mathrm{I}_{3}$ & $\mathrm{I}_{4}$ & $\mathrm{I}_{5}$ & $\mathrm{I}_{6}$ & $\mathrm{I}_{7}$ & $\mathrm{I}_{8}$ & $\mathrm{I}_{9}$ & $\mathrm{I}_{10}$ & $\mathrm{I}_{11}$ & $\mathrm{I}_{12}$ & $\mathrm{I}_{13}$ & $\mathrm{I}_{14}$ & $\mathrm{I}_{15}$ & $\mathrm{I}_{16}$ & $\mathrm{I}_{17}$ & $\mathrm{I}_{18}$ & $\mathrm{I}_{19}$ & $\mathrm{I}_{20}$ & $\mathrm{I}_{21}$ & $I_{22}$ \\
\hline$P$ & 2,57 & 3,07 & 2,94 & 2,34 & 3,26 & 3,30 & 3,27 & 3,71 & 3,10 & 3,54 & 3,58 & 4,07 & 3,59 & 3,37 & 3,47 & 3,93 & 3,35 & 3,56 & 3,31 & 1,75 & 2,39 & 3,70 \\
\hline $\bar{E}$ & 4,78 & 4,68 & 4,86 & 4,87 & 4,83 & 4,66 & 4,81 & 4,79 & 4,74 & 4,79 & 4,89 & 4,78 & 4,13 & 4,42 & 4,59 & 4,38 & 4,64 & 3,45 & 4,29 & 4,58 & 4,77 & 4,66 \\
\hline S & - & - & - & - & - & - & - & - & - & - & - & - & - & - & - & - & - & - & - & - & - & - \\
\hline 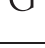 & 2,21 & 1,61 & 1,91 & 2,53 & 1,58 & 1,37 & 1,56 & 1,09 & 1,60 & 1,28 & 1,30 & 0,73 & 0,55 & 1,08 & 1,14 & 0,45 & 1,30 & 0,11 & 1,02 & 2,85 & 2,38 & 0,19 \\
\hline
\end{tabular}


Em geral, consideram-se mais críticos os itens que apresentam maiores Gaps negativos (itens em que os desempenhos do serviço foram menores que as expectativas). Entretanto, em situações em que os desempenhos do serviço à luz de todos os itens possuem valores muito altos, pode ser relevante considerar aqueles itens que geram maior expectativa. Neste contexto, para fins de gerenciamento de serviços, é usual realizar uma das ações: priorizar itens com maior Gap, priorizar itens que apresentam maior expectativa ou priorizar itens que apresentam menor desempenho percebido.

A figura 2 ilustra os Gaps existentes à luz de cada item, segundo a percepção dos alunos das engenharias e das licenciaturas. É possível verificar que os itens $\mathrm{I}_{21}, \mathrm{I}_{9}$ e $\mathrm{I}_{22}$ apresentam Gaps mais discrepantes, considerando os resultados de cada um dos grupos de respondentes. Esses itens estão relacionados ao período de funcionamento e tempo de atendimento da biblioteca e indicam que os grupos de avaliadores podem apresentar percepções e necessidades distintas.

Para melhor identificação dos itens considerados mais críticos, ou seja, a identificação dos itens que devem ter maior prioridade na identificação de falhas que comprometem a prestação do serviço, considerou-se neste estudo a Análise dos Quartis. Esta análise, proposta por Freitas et alii (2006), utiliza a medida de tendência central denominada Quartil para classificar a prioridade de cada item em regiões críticas, considerando para tal os valores de $\bar{P}, \bar{E}$ e $\bar{G}$ à luz de cada item.

Por exemplo, itens cujo desempenho médio $(\bar{P})$ sejam menores que o valor do primeiro Quartil corresponderiam a $25 \%$ do total de itens, sendo estes caracterizados como itens de "prioridade crítica" (tais itens têm prioridade crítica de ações corretivas/ preventivas). Os próximos itens mais críticos seriam aqueles cujos valores de $\bar{P}$ estariam entre o primeiro e o segundo Quartil (itens de Alta Prioridade) e assim por diante. As tabelas 4 e 5, a seguir, apresentam a classificação da prioridade dos itens obtida neste estudo.

Mais especificamente, enfatizam-se a seguir os itens considerados de prioridade crítica segundo a opinião dos alunos das engenharias e licenciaturas, em termos das suas expectativas com os serviços de uma biblioteca 'ideal', a percepção do desempenho dos serviços prestados pela biblioteca do CCT/Uenf e o Gap entre estas duas medidas.

- as expectativas: os itens mais críticos estão relacionados com a boa execução e confiabilidade dos serviços de reserva, de consulta e de empréstimo de livros (Itens $\mathrm{I}_{10}, \mathrm{I}_{12}$ e $\mathrm{I}_{22}$ ), sendo que os títulos devem ser facilmente encontrados nas estantes $\left(\mathrm{I}_{7}\right.$ e $\left.\mathrm{I}_{8}\right)$. É também desejada a existência de espaço adequado e suficiente para estudos individuais e em grupo $\left(\mathrm{I}_{3}\right.$ e $\left.\mathrm{I}_{4}\right)$. É importante

FIGURA 2

Gaps médios, segundo alunos das engenharias (a) e das licenciaturas (b)
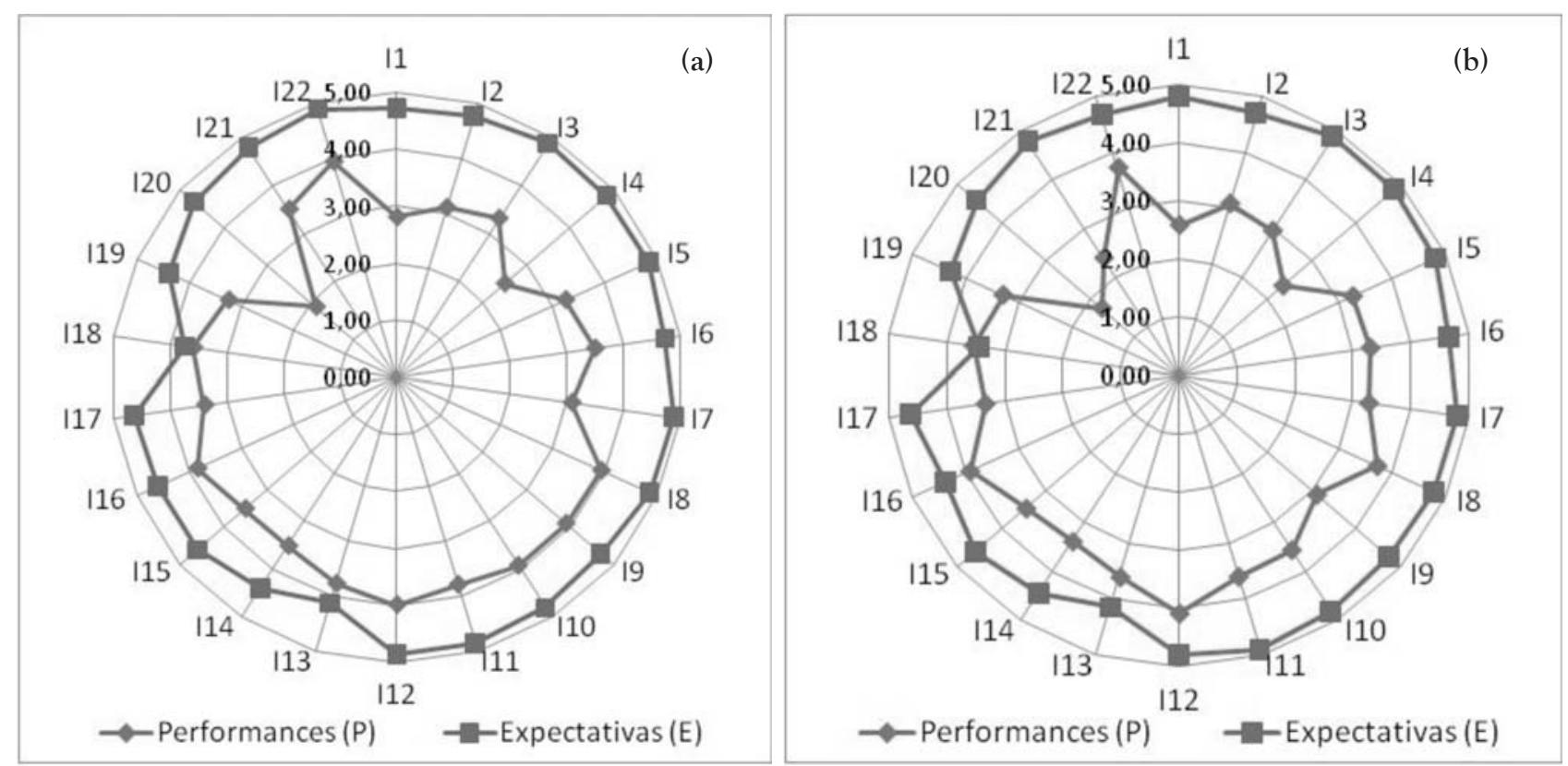

Ci. Inf., Brasília, v. 37, n. 3, p. 88-102, set./dez. 2008 
TABELA 4

Classificação das prioridades itens (percepção dos alunos das engenharias)

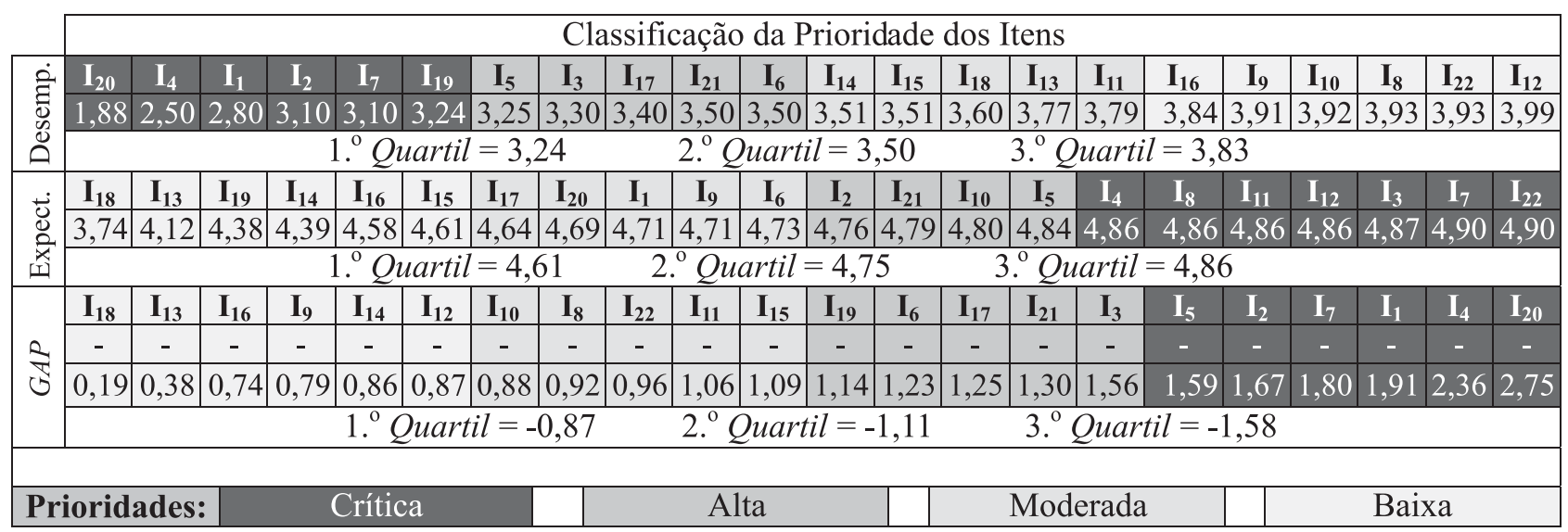

TABELA 5

Classificação das prioridades itens (percepção dos alunos das licenciaturas)

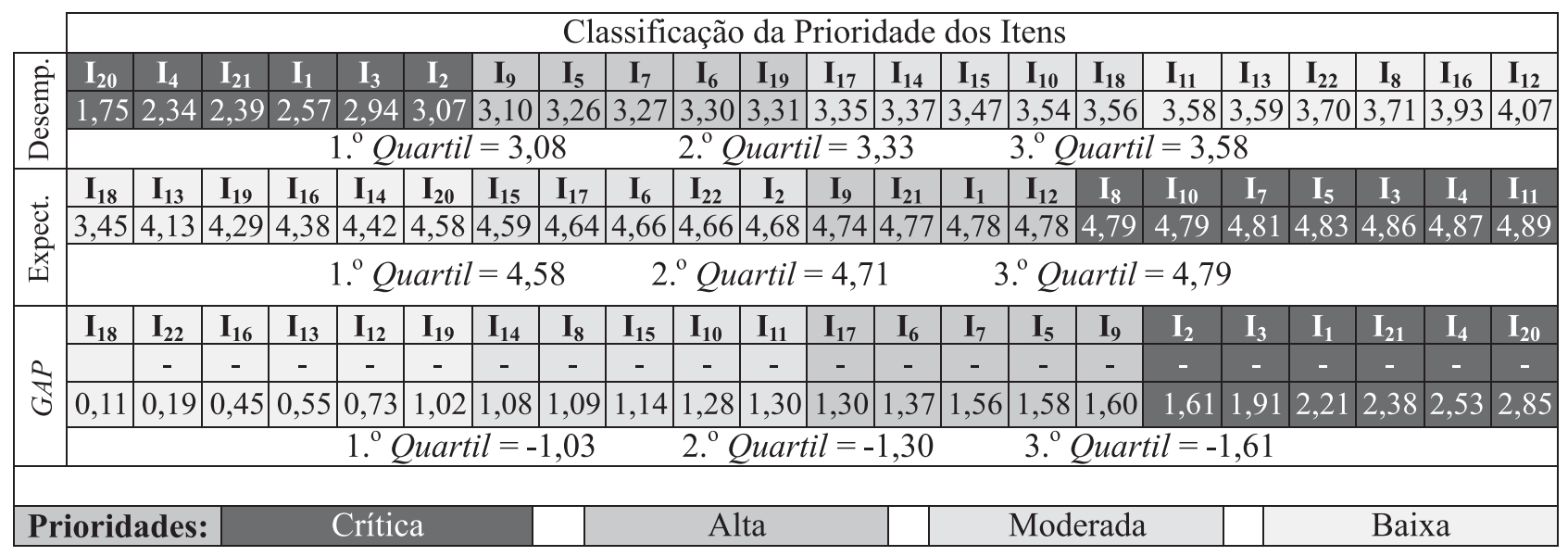

observar que estes itens representam as maiores expectativas dos usuários quanto aos serviços de bibliotecas de maneira genérica, e não de uma biblioteca específica;

- os desempenhos: o item em que a biblioteca do CCT apresenta pior desempenho segundo o ponto de vista dos usuários refere-se à quantidade de computadores com acesso à Internet $\left(\mathrm{I}_{20}\right)$. Também apresentam desempenho crítico os itens referentes ao espaço para estudo individual e em grupo (inadequado e/ou insuficiente, itens $\mathrm{I}_{3}$ e $\mathrm{I}_{4}$ ), ao horário de funcionamento (inadequado ou insuficiente para os usuários, $\mathrm{I}_{21}$ ), à modernidade dos equipamentos $\left(\mathrm{I}_{1}\right)$, à facilidade de encontrar os livros $\left(\mathrm{I}_{7}\right)$, às instalações físicas $\left(\mathrm{I}_{2}\right)$ e à existência de suporte técnico $\left(\mathrm{I}_{19}\right)$. É importante ressaltar que os itens supracitados seriam os mais críticos, caso a análise estivesse fundamentada no emprego do modelo Servperf.

- os GAPs: os Gaps representam o resultado da aplicação do modelo Servqual, sendo que os Gaps mais negativos são os considerados mais críticos e de maior prioridade (significa que a diferença entre as percepções de desempenho do serviço e as expectativas quanto ao serviço a ser prestado apresentam os valores mais negativos). Neste estudo, para efeito de análise, foram priorizados os itens classificados como de prioridade crítica e de prioridade alta. É importante observar nas tabelas 2 e 3 que alguns itens foram considerados de prioridade crítica pelos alunos dos cursos de graduação e de prioridade alta pelos alunos das licenciaturas (e vice-versa). Neste sentido, convencionou-se classificar como item de prioridade crítica aqueles itens que 
pertencessem à região critica segundo a percepção de ao menos um grupo de avaliadores (esta regra se torna relevante em problemas nos quais os usuários são estratificados em diversos grupos). Assim, os itens que possuem prioridade crítica referem-se à quantidade de computadores com acesso à Internet na biblioteca $\left(\mathrm{I}_{20}\right)$, ao espaço para estudo individual e em grupo $\left(\mathrm{I}_{3}\right.$ e $\left.\mathrm{I}_{4}\right)$, à modernidade dos equipamentos $\left(\mathrm{I}_{1}\right)$, às instalações físicas e ao ambiente da biblioteca ( $\mathrm{I}_{2}$ e $\mathrm{I}_{5}$, respectivamente), à facilidade em encontrar as obras nas estantes $\left(\mathrm{I}_{7}\right)$ e ao horário de funcionamento $\left(\mathrm{I}_{21}\right)$. De forma complementar, os itens de prioridade alta referem-se à presteza dos funcionários na solução de problemas e educação $\left(\mathrm{I}_{6} \mathrm{e}\right.$ $\left.\mathrm{I}_{17}\right)$; existência de suporte técnico $\left(\mathrm{I}_{19}\right)$ e atendimento em tempo adequado $\left(\mathrm{I}_{9}\right)$. Com o intuito de analisar criticamente estes itens mais críticos e sugerir ações de melhorias, uma reunião foi realizada com a participação do funcionário responsável pela biblioteca do CCT/ Uenf. As informações resultantes desta reunião são reportadas na seção seguinte.

Análise da prioridade dos itens e sugestões de melhorias

Em um mercado cada vez mais competitivo, torna-se cada vez mais necessário que as organizações (públicas e privadas) utilizem métodos e técnicas para gerenciamento do uso de recursos (capital, humano, material, equipamento etc.), recursos estes que são notadamente cada vez mais restritos e escassos. No contexto deste trabalho, na impossibilidade real de a organização (Uenf/ Direção do CCT) alocar seus recursos para aprimorar a qualidade dos serviços prestados pela biblioteca do CCT à luz de todos os itens críticos simultaneamente, tornase evidente a necessidade de priorizar os itens considerados mais críticos.

Neste sentido, uma reunião foi realizada com a participação do administrador (bibliotecário) da biblioteca do CCT/Uenf e os autores deste trabalho, visando a identificar as prováveis causas que evidenciaram os itens mais críticos e também propor ações de melhorias. A seguir, apresenta-se uma análise sucinta à luz de cada item:

- Item 20 (A biblioteca tem computadores suficientes com Internet): Atualmente a biblioteca possui quatro computadores disponíveis aos alunos (três com Internet e um para pesquisa ao acervo) e um ponto de rede. $\mathrm{Na}$ opinião do bibliotecário, este ponto crítico não procede, visto que os computadores visam a complementar a pesquisa acadêmica (pesquisa a periódicos e ao acervo) e para esta função eles atendem totalmente à demanda.
Como origem da criticidade, cogita-se o seguinte: (i) ineficiência/inoperância das bancadas de computadores dos cursos, fazendo com que os alunos procurem os computadores da biblioteca para digitar trabalhos, ler/ enviar e-mails e fazer pesquisas pessoais, o que não é permitido segundo as normas da biblioteca; (ii) o fato de que por muito tempo os computadores estiveram com defeito e os alunos ainda teriam esta imagem; (iii) os computadores são antigos, mas são operantes e atendem aos seus objetivos. Como ações de melhorias, citam-se (i) adicionar alguns pontos de rede e uma mesa, para que os alunos possam utilizar notebooks, e (ii) substituir os computadores antigos por novos (há espaço disponível para adicionar novos computadores aos atuais).

- Item 4 (O espaço para estudo em grupo é adequado e suficiente) - $\bigcirc$ bibliotecário tem ciência da problemática do espaço em grupo e gostaria de ampliálo, tomando o lugar atualmente ocupado pelos jardins em torno da biblioteca. Este projeto visa a construir oito salas de estudo em grupo. Entretanto, a perspectiva de esse projeto ocorrer é pequena ante a iminência da construção de uma biblioteca central. Além disso, há o agravante de que as atuais salas também são utilizadas pelos demais alunos da Universidade, o que as torna ainda mais raro encontrar vagas.

- Item 1 (A biblioteca possui equipamentos modernos) - Na biblioteca existem computadores antigos, mas que atendem ao objetivo, e há o sistema antifurto, que está desativado no momento. Ressalta-se que o bibliotecário não sabe dizer o que seriam estes equipamentos modernos que os alunos estariam esperando.

- Item 21 (A biblioteca opera em horários convenientes para todos os usuários) -Atualmente o quadro de funcionários da biblioteca é insuficiente, e não existe funcionário lotado na biblioteca para trabalhar à noite (há um funcionário deslocado de outra unidade administrativa para suprir provisoriamente esta demanda. O horário de atendimento foi reduzido em razão do afastamento de um funcionário. $\mathrm{O}$ atendimento é complementado por vários bolsistas de trabalho da própria universidade. Entretanto, o período mais crítico é o período de provas, no qual a freqüência dos alunos na biblioteca aumenta consideravelmente (vale ressaltar que os bolsistas de trabalho também são alunos e também estão em período de provas e, às vezes, faltam). Neste contexto, constata-se que existe latente necessidade de mais funcionários para atuar na biblioteca, principalmente em razão do aumento do número de alunos e de cursos nos últimos anos. 
- Item 3 (O espaço para estudo individual é adequado e suficiente) - Assim como o estudo em grupo, falta espaço para estudo individual. Entretanto, as demais bibliotecas da universidade conseguem suprir esta demanda, assim como a do CCT supre as demandas delas para estudos em grupo. Naturalmente, nos períodos de provas, a situação é mais crítica.

- Item 7 (Os livros e periódicos do acervo são facilmente encontrados nas estantes) -Este é um trabalho técnico de bibliotecário que organiza os livros por assunto mais específico, e esta é uma adoção universal. Segundo o bibliotecário, talvez esta dificuldade surja da cultura brasileira, que não é familiarizada em utilizar bibliotecas. Possíveis ações de melhorias envolvem o treinamento dos usuários, melhoria da sinalização dos livros, distribuição de folhetos explicativos e orientação dos funcionários da recepção.

- Item 2 (As instalações físicas da biblioteca são visivelmente adequadas) - Este item representa as mesmas carências identificadas nos itens relacionados ao espaço para estudos em grupo e individual. Possíveis ações de melhoria: ampliação do espaço físico e mudança de leiaute.

- Item 5 (O ambiente da biblioteca é silencioso, iluminado e arejado) - Atualmente, a iluminação da biblioteca está melhor porque todas as lâmpadas foram trocadas. O silêncio seria mantido com um tratamento acústico nas salas de estudo em grupo, além da ampliação do espaço físico. O ambiente é arejado, pois toda biblioteca é climatizada.

- Item 16 (Você confia nas informações dadas pelos funcionários da biblioteca) e Item 17 (Os funcionários da biblioteca do são gentis e educados) - O bibliotecário reconhece que as atuais condições da biblioteca fazem com que esta realidade exista. Em sua opinião, as prováveis causas para a criticidade deste item podem estar relacionadas aos seguintes aspectos: grande número de empréstimos realizados pela biblioteca do CCT (é importante ressaltar que o CCT atende à maioria das disciplinas do ciclo básico dos cursos de graduação e licenciatura da universidade), mas com o mesmo número de funcionários das demais bibliotecas, e a grande rotatividade de bolsistas que, ao aprenderem sua função trocam de tipo de bolsa (monitoria ou iniciação científica), saindo da biblioteca. Atualmente a biblioteca conta com três funcionários e seis bolsistas, para atendimento no período de oito horas da manhã às 21 horas. O treinamento dos funcionários é uma das ações possíveis.

- Item 9 (A biblioteca fornece seus serviços em tempo adequado) - Até recentemente, o tempo de atendimento era muito alto, em razão da formação de filas, principalmente nos períodos de provas. Com a disponibilização de um sistema de reservas on-line, os usuários não necessitam tanto ir à biblioteca. Segundo o bibliotecário, a movimentação da biblioteca reduziuse em um terço e a criticidade deste item não retrata a realidade atual.

Além da identificação dos itens classificados como mais críticos, do levantamento das prováveis causas de tal criticidade e das possíveis ações de melhorias, é fundamental ressaltar que nos últimos anos a quantidade de cursos oferecidos pelo CCT e, conseqüentemente, o número de alunos cresceram significativamente, não tendo o espaço físico e a quantidade de equipamentos e de funcionários de todo o Centro (incluindo-se a biblioteca do CCT) acompanhado este crescimento. Em especial, diversos cursos de licenciatura foram criados no período noturno, sendo necessário deslocar funcionários e bolsistas que atuavam no atendimento da biblioteca durante o dia para atuar em algumas horas do período noturno.

Conseqüentemente, a qualidade no atendimento aos usuários ao longo do período diurno pode ter sido comprometida. Entretanto, o tempo de atendimento no período noturno pode não ter sido suficiente, na percepção dos alunos. Quanto à consulta informatizada ao acervo no ambiente da biblioteca, esta somente é realizada pelos funcionários e bolsistas da biblioteca, que não raramente estão em número inferior à demanda de alunos. Em contrapartida, consulta semelhante pode ser feita via web (Internet), sendo possível identificar os títulos existentes em todas as bibliotecas da universidade, a quantidade, em que biblioteca da universidade se encontra e, finalmente, fazer a reserva.

\section{CONSIDERAÇÕES FINAIS}

Neste artigo buscou-se investigar o emprego da escala Servqual na avaliação da qualidade dos serviços prestados por uma biblioteca de uma universidade estadual, segundo o ponto de vista de uma amostra de usuários-alunos. Por meio de um experimento, foi possível extrair informações relevantes em análises desta natureza, tais como: 
- a expectativa dos usuários quanto aos serviços prestados por uma biblioteca à luz das dimensões e itens da qualidade; o desempenho dos serviços prestados pela biblioteca avaliada segundo a percepção de uma amostra de usuários; além de obter os Gaps provenientes da diferença entre as percepções e expectativas dos usuários;

- a Análise dos Quartis (realizada a partir dos valores dos Gaps, percepções e expectativas) permitiu classificar os itens de acordo com um nível de prioridade de ações corretivas e preventivas, com o intuito de melhorar a qualidade dos serviços prestados pela biblioteca. Em particular, esta análise pode constituir-se em uma abordagem alternativa e complementar à tradicional "Análise dos Quadrantes", que busca relacionar a importância dos itens e o desempenho (performance) dos serviços à luz dos itens.

Apesar da elevada contribuição que uma análise desta natureza pode oferecer ao prestador do serviço, é importante ressaltar que os resultados apresentados retratam apenas a avaliação da qualidade dos serviços prestados por uma determinada biblioteca em um período específico, segundo o ponto de vista de uma amostra de usuários-alunos. Os resultados obtidos não podem ser generalizados para outras situações. Neste sentido, uma análise mais conclusiva pode ser obtida a partir da continuidade das avaliações, realizadas periodicamente. Além disso, seria importante "ouvir a voz" dos clientes internos (funcionários e bolsistas) da biblioteca.

Ressalta-se também uma carência no modelo utilizado identificada pelo administrador da biblioteca e por uma parte dos usuários que participaram da pesquisa - que se refere à ausência de itens que busquem avaliar a qualidade do acervo (existência de títulos que atendam às necessidades dos projetos pedagógicos dos cursos, a quantidade e a variedade destes títulos, o estado de conservação do acervo etc.). Uma vez adicionados ao modelo, tais itens poderão fornecer informações relevantes aos coordenadores dos cursos. Entretanto, na condução da pesquisa, é importante detectar exatamente qual é o curso em que o usuário está matriculado. A nova versão do modelo contemplará esses itens adicionais.

É importante destacar que está sendo desenvolvido um formulário para coleta dos dados da avaliação dos serviços das bibliotecas pela Internet. Esse formulário é um dos instrumentos de coleta de dados desenvolvidos pelo sistema SADE - Sistema Avançado de Coleta e Análise de Dados para o Auxílio à Decisão (GONÇALVES; FREITAS, 2008) que será implementado para avaliação da qualidade dos serviços prestados pela biblioteca do CCT a partir do primeiro semestre de 2009. O emprego do modelo Servqual, apoiado pelo formulário web para coleta de dados, possui uma proposta de natureza semelhante ao uso do software LibQUAL $+\circledR$. É nessa vertente que se direciona a continuidade deste trabalho.

Finalmente destaca-se que, apesar das críticas existentes quanto ao emprego do Servqual, há de se considerar que este modelo é uma ferramenta simples e prática, contribuindo para auxiliar gestores e administradores na avaliação e no monitoramento da qualidade de serviços em ambientes corporativos. Vale ressaltar que os itens pertencentes ao questionário do modelo Servqual devem ser adaptados à natureza do serviço a ser avaliado. Estes itens devem ser bem redigidos para assegurar a compreensão dos usuários (avaliadores do serviço).

\section{Agradecimentos}

Os autores agradecem o apoio fornecido pela Fundação Carlos Chagas Filho de Amparo à Pesquisa do Estado do Rio de Janeiro (Faperj) e ao Conselho Nacional de Desenvolvimento Científico e Tecnológico (CNPq).

Artigo submetido em 01/12/2008 e aceito em 26/12/2008.

\section{REFERÊNCIAS}

ANDALEEB, S. S.; SIMMONDS, P. L. Explaining user satisfaction with academic libraries: strategic implications. College $\mathbb{E}$ Research Libraries, n. 59, p. 156-167, 1998.

ASSOCIATION OF RESEARCH LIBRARIES - ARL. LibQUAL+ ${ }^{T M}$ : defining and promoting library service quality. Disponível em: <http:/ /www.libqual.org/About/Information/index.cfm>. Acesso em: 10 out. 2008.

BABAKUS, E.; MANGOLD, G. Adapting the servqual scale to hospital services: an empirical investigation. Health Service Research, v. 26, n. 2. p. $767-786,1992$.

CARMAN, J. M. Consumer perceptions of service quality: an assessment of the Servqual dimensions. Journal of Retailing, n. 66, p.33-55, 1990 .

CHANG, P. L.; HSIEH, P. N. Customer involvement with services in public libraries. Asian Libraries, v. 6, n. 3/4, p. 242-249, 1997.

CHIVERS, B.; THEBRIDGE, S. Best value in public libraries: the role of research. Library Management, v. 21, n. 9, p. 456-465, 2000.

COOK, C.; THOMPSON, B. Reliability and validity of Servqual scores used to evaluate perceptions of library service quality. The Journal of Academic Librarianship, v. 26, n. 4, p. 248-258, 2000. 
CRONIN JR, J. J.; TAYLOR, A. S. Measuring service quality: a reexamination and an extension. Journal of Marketing, New York, v. 56, p. 55-68, July 1992.

FINN, D. W.; LAMB, C. W. An evaluation of the Servqual scales in retail setting. Advances in Consumer Research, v. 18, p. 483-490, 1991.

FREITAS, A. L. P. A qualidade de serviços no contexto da competitividade. Revista Produção on Line, v. 5, n. 1, p. 1-24, 2005.

; MANHÃES, N. R. C.; COZENDEY, M. I. Emprego do Servqual na avaliação da Qualidade de Serviços de Tecnologia da Informação: uma análise experimental. In: ENEGEP, 26., 2006. Anais... 2006. p. 1-8.

GATTEN, J. N. Measuring Consortium impact on user perceptions: OhioLINK and LibQUAL+TM. The Journal of Academic Librarianship, v. 30, n. 3, p. 222-228, 2004.

GONÇALVES, T. J. M.; FREITAS, A. L. P. SADE: Sistema Avançado de Coleta e Análise de Dados para o Auxílio à Decisão. Versão 1.0. Disponivel em: 〈http://www.sistemasade.com.br $>$. Acesso em: 30 out. 2008.

INSTITUTO NACIONAL DE ESTUDOS E PESQUISAS EDUCACIONAIS ANÍSIO TEIXEIRA - INEP. SINAES - Sistema Nacional de Avaliação da Educação Superior: da concepção à regulamentação. 2. ed. Brasília, 2004. 155 p. 2006. 96 p.

Instrumento de avaliação de cursos de graduação. Brasília,

MATTAR, F. N. Pesquisa de marketing: metodologia e planejamento. 5. ed. São Paulo: Atlas, 1996. 320 p.

NITECKI, D. A.; HERNON, P. Measuring service quality at Yale's University's Libraries. The Journal of Academic Librarianship, v. 26, n. 4, p. 259-273, 2000.

PARASURAMAN, A.; ZEITHAML, V. A.; BERRY, L. L. A conceptual model of service quality and its implications for future research. Journal of Marketing, Chicago, v .49, n. 3, p. 41-50, 1985.

Reassessment of expectations as a comparison standard in measuring service quality: implications for further research. Journal of Marketing, v. 58, p. 111-24, Jan. 1994.

Servqual: A multiple-item scale for measuring consumer perceptions of service quality. Journal of Retailing, New York, v. 64, n. 1, p. 12-40, Spring 1988.

SATOH, Y. et al. Evaluation of the university library service quality: analysis through focus group interviews. Performance Measurement and Metrics, v. 6, n. 3, p. 183-193, 2005.

SNOJ, B.; PETERMANEC, Z. Let users judge the quality of faculty library services. New Library World, v. 102, n. 1168, p. 314-324, 2001. 


\section{Anexo: Modelo de Questionário.}

Indique o grau que você acha que bibliotecas deveriam apresentar as características descritas em cada enunciado (itens 1 a 22). Se você concorda totalmente que bibliotecas devam ter uma certa característica, marque 5. Caso você discorde totalmente que bibliotecas devam ter tal característica, marque 1. Em situações intermediárias, marque valores entre 2 e 4 . Não há respostas certas ou erradas.

Discordo totalmente (1)

Neutro (3)

Concordo totalmente (5)

1. Bibliotecas devem possuir equipamentos modernos.

2. Suas instalações físicas devem ser visivelmente adequadas.

3. $\mathrm{O}$ espaço para estudo individual deve ser adequado e suficiente.

4. O espaço para estudo em grupo deve ser adequado e suficiente.

5. O ambiente de bibliotecas deve ser silencioso, iluminado e arejado.

6. Se você tem problemas, os funcionários devem ser solidários e prestativos.

7. Os livros e periódicos do acervo devem ser facilmente encontrados nas estantes.

8. Bibliotecas devem ser informatizadas para facilitar a busca (por título, autor etc.).

9. Bibliotecas devem fornecer seus serviços em tempo adequado.

10. O serviço de reserva de livro (agendamento) deve ser bem executado.

11. Bibliotecas devem manter seus registros atualizados.

12. Os serviços de consulta e empréstimos precisam ser confiáveis.

13. Você deve ser atendido imediatamente pelos funcionários de bibliotecas.

14. Os funcionários de bibliotecas nem sempre precisam estar dispostos a ajudá-lo.

15. Os funcionários da biblioteca precisam conhecer bem o acervo.

16. Você deve confiar nas informações dadas por funcionários de bibliotecas.

17. Os funcionários de bibliotecas precisam ser gentis e educados.

18. Os funcionários de bibliotecas devem apresentar boa aparência.

19. Os funcionários precisam ter suporte técnico para executar bem as tarefas.

20. Deve-se esperar que bibliotecas tenham computadores suficientes com Internet.

21. Deve-se esperar que bibliotecas funcionem em horários convenientes a todos usuários

22. Deve-se esperar que bibliotecas funcionem exatamente nos horários divulgados. 
Indique o grau que você acha que a biblioteca do CCT/Uenf apresenta as características descritas em cada enunciado (itens 1 a 22). Se você concorda totalmente que a biblioteca do CCT/UENF possui uma certa característica, marque 5. Se você discorda totalmente que a biblioteca do CCT/UENF possui tal característica, marque 1. Em situações intermediárias, marque valores entre 2 e 4 . Não há respostas certas ou erradas.

Discordo totalmente (1)

$$
\text { Neutro (3) }
$$

1. A biblioteca do CCT possui equipamentos modernos.

2. As instalações físicas da biblioteca do CCT são visivelmente adequadas.

3. O espaço para estudo individual é adequado e suficiente.

4. O espaço para estudo em grupo é adequado e suficiente.

5. O ambiente da biblioteca do CCT é silencioso, iluminado e arejado.

6. Se você tem dúvidas, os funcionários da biblioteca do CCT são solidários/prestativos.

7. Os livros e periódicos do acervo são facilmente encontrados nas estantes.

8. A biblioteca do CCT é informatizada. A busca (por título, autor etc.) é facilitada.

9. A biblioteca do CCT fornece seus serviços em tempo adequado.

10. O serviço de reserva de livro (agendamento) é bem executado.

11. A biblioteca do CCT mantém seus registros atualizados.

12. Os serviços de consulta e empréstimo são confiáveis.

13. Você não é atendido imediatamente pelos funcionários da biblioteca do CCT.

14. Os funcionários da biblioteca do CCT nem sempre estão dispostos a ajudá-lo.

15. Os funcionários da biblioteca do CCT demonstram conhecer bem o acervo.

16. Você confia nas informações dadas pelos funcionários da biblioteca do CCT.

17. Os funcionários da biblioteca do CCT são gentis e educados.

18. Os funcionários da biblioteca do CCT apresentam boa aparência.

19. Funcionários da biblioteca do CCT têm apoio técnico para executar bem as tarefas

20. A biblioteca do CCT tem computadores suficientes com Internet.

21. A biblioteca do CCT opera em horários convenientes para todos os usuários.

22. A biblioteca do CCT funciona exatamente nos horários divulgados. 